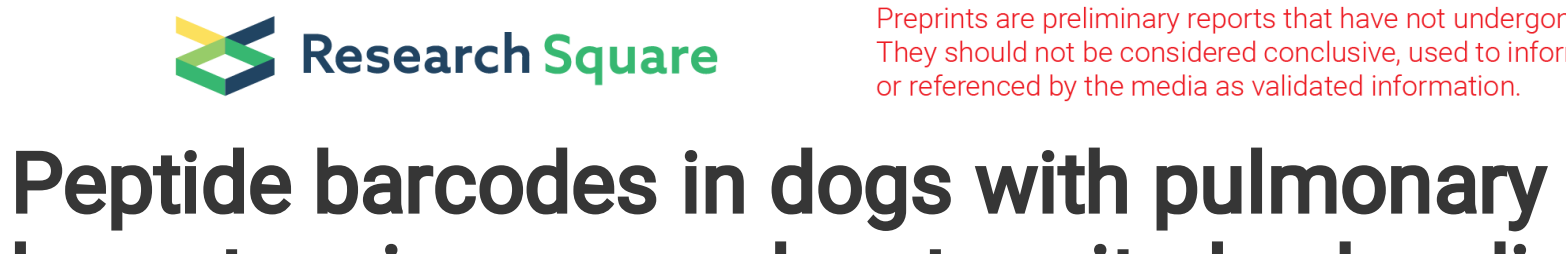 \\ hypertension secondary to mitral valve disease \\ using MALDI-TOF MS and LC-MS/MS
}

Nattapon Riengvirodkij

Mahidol University

\section{Sittiruk Roytrakul}

Biotec: National Center for Genetic Engineering and Biotechnology

Janthima Jaresitthikunchai

Biotec: National Center for Genetic Engineering and Biotechnology

Narumon Phaonakrop

Biotec: National Center for Genetic Engineering and Biotechnology

Sawanya Charoenlappanich

Biotec: National Center for Genetic Engineering and Biotechnology

Walasinee Sakcamduang ( $\nabla$ walasinee.sak@mahidol.edu )

Mahidol University https://orcid.org/0000-0002-8245-9506

\section{Research article}

Keywords: Dog, Liquid chromatography tandem mass spectrometry (LC-MS/MS), Matrix-assisted laser desorption/ionization time-of-flight mass spectrometry (MALDI-TOF MS), Mitral valve disease, Pulmonary hypertension

Posted Date: December 29th, 2020

DOI: https://doi.org/10.21203/rs.3.rs-135232/v1

License: (1) This work is licensed under a Creative Commons Attribution 4.0 International License. Read Full License 


\section{Abstract \\ Background}

Pulmonary hypertension $(\mathrm{PH})$ is an important complication in dogs with cardiorespiratory diseases. The most common underlying disease of $\mathrm{PH}$ has been described to be mitral valve disease (MVD), which is the most frequent acquired heart disease found in dogs. Doppler echocardiography is generally used in routine practice for identifying $\mathrm{PH}$; however, there are several limitations to this method in practical use. Matrix-assisted laser desorption/ionization time-of-flight mass spectrometry (MALDI-TOF MS) is a technique that can characterize specific patterns of peptide mass called peptide barcodes from various samples. In addition, in combination with liquid chromatography tandem mass spectrometry (LC$\mathrm{MS} / \mathrm{MS}$ ), potential peptide sequences associated with specific conditions could be identified. The present study aimed to use MALDI-TOF coupled with LC-MS/MS to characterize specific peptide barcodes and potential peptide candidates in serum samples from healthy dogs (normal control), dogs with MVD stage $B$ (MVD B) (asymptomatic stage), MVD stage C (MVD C) (symptomatic stage), MVD stage B with PH (MVD B PH) and MVD stage $C$ with PH (MVD C PH).

\section{Results}

Discrete clusters of the 5 sample groups were identified by 3D plot analysis. Peptide barcodes also revealed differences in peptide patterns among the 5 groups. Six amino acid sequences of peptide candidates at 1,225.60, 1,363.85, 1,688.71, 1789.52, 2020.21 and 2156.42 Da were identified as part of the proteins CLCN1, CLUL1, EDNRA, PTEN, SLC39A7, and CLN6, respectively. The network interactions between these discovered proteins and common cardiovascular drugs were also investigated.

\section{Conclusion}

The present study revealed distinct clusters and different peptide barcodes for the MVD B, MVD C, MVD B $\mathrm{PH}, \mathrm{MVD} \mathrm{C} \mathrm{PH}$ and normal control groups using MALDI-TOF MS. These results demonstrate that MALDITOF MS has promise as a technique for diagnosing dogs affected by asymptomatic and symptomatic stages of MVD with and without PH. Additionally, with MALDI-TOF MS in combination with LC-MS/MS, potential peptide candidates related to diseases were also identified. Further studies are required to identify peptide barcodes in dogs with other diseases to create peptide barcode databases in veterinary medicine before using this method as a novel diagnostic tool in the future.

\section{Background}

Pulmonary hypertension $(\mathrm{PH})$ is a pathologic condition defined as increased blood pressure in the pulmonary vascular system $(1,2)$. $\mathrm{PH}$ can occur as primary (idiopathic) or secondary $\mathrm{PH}$, which could have various underlying causes $(3,4)$. The most common underlying cause of $\mathrm{PH}$ has been described to 
be left-sided heart disease $(1,5,6)$. This study will focus only on $\mathrm{PH}$ associated with mitral valve disease (MVD), which is the most common acquired left-sided heart disease in dogs (7). MVD is highly prevalent in small-breed dogs, particularly in older dogs, with a prevalence of up to $90 \%$ in small-breed dogs older than 8 years old $(7)$.

The gold standard for the definitive diagnosis of $\mathrm{PH}$ is cardiac catheterization of the right heart to measure the pulmonary arterial pressure (PAP) directly in the pulmonary vasculature (8), but in general veterinary practice, echocardiography is more generally used in the diagnosis of $\mathrm{PH}$, as well as in MVD (9, 10). However, there are some limitations to this technique, including the high cost of the echocardiography machine and the need for a well-trained sonographer to perform the procedure. The differentiation between asymptomatic and symptomatic MVD is also challenging. The diagnosis of symptomatic MVD is based on the detection of left-sided congestive heart failure (CHF) signs from physical examination, such as respiratory distress, tachypnoea, and cough (11), which are nonspecific and could also be found in patients with concomitant respiratory diseases. The presence of pulmonary oedema in the perihilar region as observed by thoracic radiography is generally used for detecting leftsided CHF. However, this procedure is limited when patients have severe respiratory distress, as restraint for radiography should be avoided in these patients. Determination of the serum N-terminal pro B-typenatriuretic peptide (NT-proBNP) level has been added as adjunctive test for diagnosing both symptomatic MVD and PH. Unfortunately, the NT-proBNP concentration alone is insufficient to be used for identifying $\mathrm{PH}(11-13)$ and differentiating symptomatic from subclinical MVD $(14,15)$. According to these limitations, another method is required to be investigated for developing an alternative technique to detect $\mathrm{PH}$ in veterinary medicine.

In recent years, MALDI-TOF MS has been introduced as a novel instrument used in clinical diagnosis in both human and veterinary medicine due to its rapidity of interpretation, high efficacy and costeffectiveness (16). MALDI-TOF is a potent method with great capability for identifying patterns of peptide mass called peptide barcodes in many types of samples (e.g., serum, saliva, sweat and tissue). The obtained peptide barcode is typically unique to each condition or disease. Therefore, these peptide barcodes can be used to recognize diseases and serve as alternative diagnostic tools in clinical practice. At present, MALDI-TOF has been applied in human medicine as a diagnostic test, especially in the field of neoplastic diseases, for early diagnosis, monitoring and mechanistic determination. It is used to detect numerous types of cancer in the early stage of disease, including gastrointestinal cancer (17), lung cancer (18), renal cell carcinoma (19), bladder cancer (20), prostate cancer $(21,22)$, breast cancer (2325) and leukaemia (26). In veterinary medicine, MALDI-TOF has been evaluated to characterize unique peptide barcodes in dogs with different oral tumours using oral tumour tissues (27) and saliva samples (28). Another technique that is commonly used in peptidomic studies is liquid chromatography tandem mass spectrometry (LC-MS/MS). This method has the ability to identify peptide sequences from various samples. To our knowledge, the study of peptide barcodes and the identification of potential peptide sequences using MALDI-TOF coupled with LC-MS/MS in dogs with MVD with or without PH has never been evaluated. The present study aimed to demonstrate peptide barcode and peptide candidates associated with each condition that could potentially be developed as novel diagnostic biomarkers 
obtained from serum samples in healthy dogs (normal control group), dogs with MVD stage B (MVD B group) (asymptomatic stage), MVD stage C (MVD C group) (symptomatic stage), MVD stage B with PH (MVD B PH group) and MVD stage $\mathrm{C}$ with $\mathrm{PH}$ (MVD C PH group).

\section{Results}

Fifty-nine dogs were enrolled in the study. They were classified into 5 groups according to the American College of Veterinary Internal Medicine (ACVIM) classification (29), including 16 dogs with MVD stage B2 (MVD B), 5 dogs with stage B2 and PH (MVD B PH), 11 dogs with MVD stage C (MVD C), 16 dogs with MVD stage $C$ and PH (MVD C PH), and 11 normal control dogs. The MVD B group $(n=16)$ consisted of 2 Shih-Tzus, 5 Poodles, 3 mixed-breed dogs, 3 Pomeranians, 2 Chihuahuas and 1 Dachshund. The MVD C group ( $n=11$ ) included 3 Chihuahuas, 2 Poodles, 3 mixed-breed dogs, 2 Shih-Tzus and 1 Pomeranian. The MVD B PH group $(n=5)$ comprised 3 Chihuahuas, 1 Poodle and 1 Shih-Tzu. The MVD C PH group $(n=16)$ consisted of 9 Poodles, 2 Chihuahuas, 2 Pomeranian and 1 each of the following breeds: Shih-Tzu, Golden Retriever and mixed-breed dog. The normal control group $(n=11)$ included 2 Poodles, 8 Chihuahuas and 1 Pomeranian. The baseline characteristics of all 59 dogs are reported in Table 1. The median body weight, proportion of females versus males and percentage of fractional shortening (FS\%) were not significantly different among the groups, whereas the median age, left atrium-to-aorta (LA:Ao) ratio, normalized end-diastolic left ventricular internal diameter (NLVIDd) and normalized end-systolic left ventricular internal diameter (NLVIDs) were shown to be significantly different among the groups. The normal dogs were significantly younger than the dogs in the other groups. Compared with normal dogs, dogs with MVD stage $B, M V D$ stage $C$ and MVD stage $C$ with $P H$ had a significantly increased LA:Ao ratio, NLVIDd and NLVIDs. Dogs with MVD stage $C$ with or without $\mathrm{PH}$ had an increased LA:Ao ratio compared to dogs with MVD stage $B$ with or without $P H$. Dogs with MVD stage $C$ showed a significantly higher NLVIDd and NLVIDS than dogs with MVD stage $B$ with and without $\mathrm{PH}$.

Table 1 Baseline characteristics of the 59 dogs in all groups. 


\begin{tabular}{|c|c|c|c|c|c|c|}
\hline Variables & $\begin{array}{l}\text { MVD B } \\
(n=16)\end{array}$ & $\begin{array}{l}\text { MVD B PH } \\
(n=5)\end{array}$ & $\begin{array}{l}\text { MVD C } \\
(\mathrm{n}=11)\end{array}$ & $\begin{array}{l}\text { MVD C PH } \\
(n=16)\end{array}$ & $\begin{array}{l}\text { Normal } \\
(n=11)\end{array}$ & $\begin{array}{l}P \\
\text { value }\end{array}$ \\
\hline $\begin{array}{l}\text { Age } \\
\text { (years) }\end{array}$ & $\begin{array}{l}11.8^{\mathrm{a}}(9.1- \\
14.3)\end{array}$ & $\begin{array}{l}12.0^{\mathrm{a}}(8.3- \\
13.5)\end{array}$ & $\begin{array}{l}10.3^{\mathrm{a}}(10- \\
12.5)\end{array}$ & $\begin{array}{l}11.8^{a}(10.8- \\
12.9)\end{array}$ & $5.0^{\mathrm{b}}(5-7.79)$ & 0.003 \\
\hline $\begin{array}{l}\text { Body } \\
\text { weight } \\
\text { (kg) }\end{array}$ & $\begin{array}{l}5.4(4.05- \\
8.35)\end{array}$ & $5.3(4-5.8)$ & $\begin{array}{l}4.7(4.25- \\
6.8)\end{array}$ & $\begin{array}{l}5.45(4.3- \\
7.78)\end{array}$ & $\begin{array}{l}3.7(3.15- \\
5.15)\end{array}$ & 0.233 \\
\hline $\begin{array}{l}\text { Female } \\
\text { (percent) }\end{array}$ & $\begin{array}{l}6 / 16 \\
(37.5 \%)\end{array}$ & $2 / 5(40 \%)$ & $\begin{array}{l}5 / 11 \\
(45.5 \%)\end{array}$ & $\begin{array}{l}6 / 16 \\
(37.5 \%)\end{array}$ & 7/11 (63.6) & 0.679 \\
\hline $\begin{array}{l}\text { LA:Ao } \\
\text { ratio }\end{array}$ & $\begin{array}{l}1.69^{\mathrm{a}}(1.5- \\
1.97)\end{array}$ & $\begin{array}{l}1.70^{\mathrm{ac}}(1.22- \\
1.88)\end{array}$ & $\begin{array}{l}2.06^{b}(1.83- \\
2.21)\end{array}$ & $\begin{array}{l}2.01^{b}(1.95- \\
2.69)\end{array}$ & $\begin{array}{l}1.27^{c}(1.11- \\
1.37)\end{array}$ & $<0.001$ \\
\hline $\begin{array}{l}\text { NLVIDd } \\
(\mathrm{cm})\end{array}$ & $\begin{array}{l}1.71^{\mathrm{a}}(1.49- \\
1.88)^{(1.4}\end{array}$ & $\begin{array}{l}1.49^{\mathrm{ac}}(1.33- \\
1.58)\end{array}$ & $\begin{array}{l}1.96^{\mathrm{b}}(1.79- \\
2.11)\end{array}$ & $\begin{array}{l}1.91^{\mathrm{ab}}(1.56- \\
2.31)\end{array}$ & $\begin{array}{l}1.36^{\mathrm{c}}(1.28- \\
1.41)\end{array}$ & $<0.001$ \\
\hline $\begin{array}{l}\text { NLVIDs } \\
(\mathrm{cm})\end{array}$ & $\begin{array}{l}0.81^{\mathrm{a}}(0.75- \\
0.92)\end{array}$ & $\begin{array}{l}0.74^{a}(0.63- \\
0.83)\end{array}$ & $\begin{array}{l}0.97^{\mathrm{b}}(0.89- \\
1.09)\end{array}$ & $\begin{array}{l}0.94^{\mathrm{ab}}(0.79- \\
1.12)\end{array}$ & $\begin{array}{l}0.74^{\mathrm{ac}}(0.66- \\
0.82)\end{array}$ & 0.024 \\
\hline FS (\%) & $\begin{array}{l}48.38 \\
(44.49- \\
56.74\end{array}$ & $\begin{array}{l}48.51 \\
(48.32- \\
42.38)\end{array}$ & $\begin{array}{l}45.35 \\
(41.77- \\
54.53)\end{array}$ & $\begin{array}{l}50.38 \\
(46.32- \\
54.45)\end{array}$ & $\begin{array}{l}42.11 \\
(38.86- \\
48.94)\end{array}$ & 0.289 \\
\hline
\end{tabular}

Data are reported as the median (Q1-Q3), and the female sex is reported as the proportion (percent).

Bold $p$ values indicate significance $(P$ value $<0.05)$.

Within the same row, values with the same letter in superscript do not differ significantly ( $P$ value $>0.05$ ).

LA:Ao left atrium-to-aorta ratio, NLVIDd normalized end-diastolic left ventricular internal diameter, NLVIDs normalized end-systolic left ventricular internal diameter, FS\% fractional shortening percentage

\section{Peptide barcodes by MALDI-TOF}

The 3-dimensional view of the principal component analysis (3D-PCA) scatterplot revealed distinct clusters among the MVD B, MVD C, MVD B PH, MVD C PH and normal control groups. All 36 replicates from each pooled serum sample group exhibited a clearly distinguished cluster from the others, indicating a distinctive peptide profile in each individual group and demonstrating the uniformity and homogeneity of data within the groups (Fig. 1). Thirty-six dots with different colours represent the replicated pooled serum samples within each group. Different peptide barcodes in the MVD B, MVD C, MVD B PH, MVD C PH and normal control groups were identified with a detection range of 1,000-20,000 Da (Fig. 2). The MALDI-TOF MS results indicated accurate outcomes with $95 \%$ confidence intervals. The cross-validation result, calculated by ANOVA, in the MVD B, MVD B PH, MVD C, MVD C PH and normal groups was $93.33 \%, 100 \%, 100 \%, 100 \%$ and $100 \%$, respectively, and the recognition capability calculated 
by QC/Different Average, SNN, AD, TTA, W/KW, and Genetic Algorithm in the MVD B, MVD B PH, MVD C, MVD C PH and normal groups was $100 \%$ for each, indicating that the results were of high reliability.

Different mass spectral peaks of peptide barcodes among all 5 groups were selected and demonstrated by ClinPro Tools software, including peptide $A$ with a mass spectral peak at 1,225.60 Da, peptide B with a mass spectral peak at $1,363.85 \mathrm{Da}$, peptide $C$ with a mass spectral peak at $1,688.71 \mathrm{Da}$, peptide $\mathrm{D}$ with a mass spectral peak at 1,789.52 Da, peptide $E$ with a mass spectral peak at 2,020.21 Da, peptide $F$ with a mass spectral peak at 2,156.42 Da (Fig. 3).

\section{Peptide identification by MALDI-TOF and LC-MS/MS}

Mass spectral peaks with high signal intensities in all sample groups were further analysed by LCMS/MS. Peptide A, with a mass spectral peak at 1,225.60 Da, was identified as part of chloride channel protein 1 (CLCN1). Peptide B, with a mass spectral peak at 1,363.85 Da, was identified as part of clusterin-like protein 1 precursor (CLUL1). Peptide C, with a mass spectral peak at 1,688.71 Da, was identified as part of endothelin-1 receptor precursor (EDNRA). Peptide D, with a mass spectral peak at 1,789.52 Da, was identified as part of phosphatidylinositol-3,4,5-trisphosphate 3-phosphatase and dualspecificity protein phosphatase (PTEN). Peptide E, with a mass spectral peak at 2,020.21 Da, was identified as part of zinc transporter SLC39A7 (SLC39A). Peptide F, with a mass spectral peak at 2,156.42 Da, was identified as part of ceroid-lipofuscinosis neuronal protein 6 homologue (CLN6) (Table 2). Networks of protein-protein and protein-cardiovascular drug interactions were evaluated by the Stitch program, version 5.0. The strength of these pathway interactions at the functional level was assessed by edge confidence scores. Interactions with high edge confidence scores $(>0.700)$ are represented as thick lines, indicating strong relationships for the protein-protein and/or protein-cardiovascular drug interactions. Four out of 6 proteins, including CLCN1, EDNRA, PTEN and SLC39A7, revealed strong relationships with cardiovascular drugs that are commonly used clinically. These include furosemide, ramipril, benazepril, imidapril, pimobendan, spironolactone and sildenafil. The remaining 2 proteins, CLUL1 and CLN6, showed no association or interaction with any cardiovascular drug (Fig. 4).

Table 2 Amino acid sequence of peptide candidates from Figure 4 analysed by LC-MS/MS 


\begin{tabular}{|c|c|c|c|c|}
\hline \multirow[t]{2}{*}{ Peptide } & \multirow{2}{*}{$\begin{array}{l}\text { Mass } \\
(\mathrm{Da})\end{array}$} & \multirow[t]{2}{*}{ Amino acid sequence } & \multicolumn{2}{|c|}{ Expected protein } \\
\hline & & & $\begin{array}{l}\text { UniProt } \\
\text { accession } \\
\text { No. }\end{array}$ & Protein name \\
\hline A & 1225.689 & GLRANTRPTQI & Q9MZT1 & $\begin{array}{l}\text { Chloride channel protein } 1 \text { (ClC-1) } \\
\text { (CLCN1) }\end{array}$ \\
\hline B & 1363.768 & TNLMKTLKKCK & Q95KN1 & $\begin{array}{l}\text { Clusterin-like protein } 1 \text { (retinal- } \\
\text { specific clusterin-like protein) } \\
\text { (CLUL 1) }\end{array}$ \\
\hline C & 1688.939 & GDLIYVVIDLPINVF & Q5KSU9 & $\begin{array}{l}\text { Endothelin-1 receptor (endothelin } \\
\text { receptor type A) (ET-AR) (EDNRA) }\end{array}$ \\
\hline D & 1789.007 & IKVEFFHKQNKMLK & P60483 & $\begin{array}{l}\text { Phosphatidylinositol 3,4,5- } \\
\text { trisphosphate } 3 \text {-phosphatase and } \\
\text { dual-specificity protein } \\
\text { phosphatase (PTEN) }\end{array}$ \\
\hline E & 2020.193 & LLREASPLQSLLEVLGLLG & Q5TJF6 & $\begin{array}{l}\text { Zinc transporter SLC39A7 } \\
\text { (SLC39A7) }\end{array}$ \\
\hline $\mathrm{F}$ & 2156.215 & LWNDPVLRKKYPGVIYVP & Q5JZQ8 & $\begin{array}{l}\text { Ceroid-lipofuscinosis neuronal } \\
\text { protein } 6 \text { homologue (CLN6) }\end{array}$ \\
\hline
\end{tabular}

Abbreviations: ACE, angiotensin-converting enzyme; AKT1, v-akt murine thymoma viral oncogene homologue 1; CLCN1, chloride channel protein 1; CLN6, ceroid-lipofuscinosis neuronal protein 6 homologue; CLUL1, clusterin-like protein 1 precursor; EDN-1, endothelin-1; EDNRA, endothelin-1 receptor precursor; InsP3, intracellular messenger formed by the action of phospholipase $\mathrm{C}$ on phosphatidylinositol 4,5-bisphosphate; PDE5A, phosphodiesterase 5; Ptdlns, phosphatidic acid combined with inositol; PTEN, phosphatidylinositol-3,4,5-trisphosphate 3-phosphatase and dual-specificity protein phosphatase; PTK2, protein tyrosine kinase 2; SLC39A7, zinc transporter SLC39A7.

\section{Discussion}

To our knowledge, this is the first study to analyse peptide barcodes using the MALDI-TOF method in dogs affected by different stages of MVD with and without $\mathrm{PH}$. Echocardiography, the conventional method for the identification of both MVD and PH in dogs, requires a high-cost machine and well-trained sonographer to perform the examination and interpret the results; in addition, the differentiation between asymptomatic and symptomatic MVD in dogs is very challenging due to the nonspecificity of the clinical signs. MALDI-TOF MS is a promising method for detecting MVD with and without $\mathrm{PH}$ in dogs by using serum samples, which are easy to collect; furthermore, the results do not require expert skill for interpretation. MALDI-TOF MS is a fast, accurate and reliable method with high sensitivity and high reproducibility. Moreover, it is less expensive than echocardiography for the identification of both MVD and $\mathrm{PH}$ in dogs, making it appropriate for the clinical diagnosis of MVD and PH in dogs. The analysis of peptides with MALDI-TOF also allows multiple groups of peptides to be identified at once. In contrast, 
conventional methods, such as ELISA, can only analyse one type of peptide at a time. For this reason, peptide barcodes derived from MALDI-TOF MS have more potential for diagnosing diseases than conventional ELISA techniques. Peptide barcodes are determined by an analytical technique for demonstrating different peaks of peptides that are usually unique to each condition (e.g., disease) or organism (e.g., bacteria, fungi or plants). The present study demonstrated differences in the serum peptide barcodes of dogs in the MVD B, MVD C, MVD B PH, MVD C PH and normal control groups using MALDI-TOF MS. Peptides derived from proteins were altered in their abandon, representing changes in the protein levels of peptide barcode components among the groups. Additionally, the scatterplot analysis by MALDI-TOF MS exhibited discrete clusters of peptide expression in each sample group. According to these results, MALDI-TOF has potential for use as a rapid and efficient method for detecting $\mathrm{PH}$ and differentiating between symptomatic and asymptomatic MVD.

Peptide barcodes obtained from MALDI-TOF have been reported as an alternative tool for detecting human breast cancers. Kang et al. (30) investigated the protein MALDI profile of 34 pairs of resected breast cancer and adjacent normal tissue samples. The results showed that the peptide profile could noticeably discriminate breast cancer from normal tissue samples. In another study, MALDI-TOF MS was used to create a peptide profile reference for the classification of various cancer cell lines, such as human melanoma, human breast carcinoma and human liver carcinoma cell lines. The results revealed different peptide barcodes in each cancer cell line that could be used to identify the types of cancer in patients clinically (31). In veterinary medicine, peptide barcodes have also been demonstrated to be used for classifying different types of canine oral tumours using tumour tissue samples (27) and salivary samples (28). A study using peptide barcodes for the diagnosis of canine heart disease has never been performed; thus, this study is the first to define peptide barcodes specific to different stages of MVD with and without $\mathrm{PH}$ in dogs.

NT-proBNP has been defined as a cardiac biomarker for the diagnosis, therapeutic monitoring and prognosis of MVD in dogs $(14,15,32-35)$. NT-proBNP is an amino terminal fragment of prohormone, proBNP, consisting of 76 amino acids (36). The exact molecular weight of NT-proBNP has never been reported, although, using a tool on the ExPASy server (https://web.expasy.org/compute_pi/pi_tooldoc.html), the molecular weight of NT-proBNP can be calculated as approximately 8,087 Da. However, no mass spectral peak at this molecular weight was detected in our samples; therefore, this could indicate that peptide sequences within all mass spectral peaks at different molecular weights were not NT-proBNP. Another cardiac biomarker that has been clinically used for identifying heart disease is cardiac troponin I (cTnl). In veterinary medicine, an elevated cTnl concentration suggests the presence of myocardial injury (37). However, it does not classify the cause of injury. cTnl has also been reported to be significantly increased in dogs with pre-capillary PH compared to normal dogs and dogs with MVD (13). cTnl has a molecular weight of 24,000 Da (38), which is larger than all mass spectral peaks obtained from this study. No peptide with a similar sequence to cTnl and NT-proBNP was detected by LC-MS, implying that peptides detected by MALDI-TOF might be used as new cardiac biomarkers. 
NT-proBNP is produced inside ventricular myocytes by the cleavage of pro-BNP, a 108-amino acid prohormone, via 2 proteolytic enzymes, furin and corin. The cleavage of proBNP is believed to occur during the peptide secretion process (39). cTnl is an intracellular cardiac protein that involves the troponin complex to prevent an interaction between actin and myosin during the relaxation of cardiac muscle. This protein is released into the circulation when cardiomyocyte injury occurs. Novel peptides that we could identify from each mass spectral peak in the present study may be synthesized and secreted into the circulation by a process similar to that of these 2 previous peptides.

Amino acid sequences of peptide candidates from discriminatory mass spectral peaks were analysed by LC-MS/MS. Six amino acid sequences of peptide candidates were identified (peptides A-F), as shown in Table 2. These obtained peptide candidates with mass spectral peaks at 1,225.60, 1,363.85, 1,688.71, 1789.52, 2020.21 and 2156.42 Da were found to be part of the proteins CLCN1, CLUL1, EDNRA, PTEN, SLC39A7, and CLN6, respectively. CLCN1 is the voltage-gated chloride ion channel protein. It is located in the cell membrane and is known to be involved in the repolarization of skeletal muscle cells (40). CLUL1 is a clusterin-like protein. Its alternative name is retinal-specific clusterin-like protein because it is mainly localized in retinal cone photoreceptor cells (41). However, its molecular function in dogs is still unclear. Furthermore, EDNRA is an endothelin-1 receptor that can be classified into 2 subtypes: endothelin receptor type $A\left(E T_{A}\right)$ (42) and endothelin receptor type $B\left(E T_{B}\right)(43)$. $E T_{A}$ is predominantly located on vascular smooth muscle cells. $\mathrm{ET}_{\mathrm{B}}$ is mostly abundant on endothelial cells, followed by smooth muscle cells to some extent. When endothelin-1 (ET-1) activates both receptors on vascular smooth muscle cells, vasoconstriction is induced, and smooth muscle cells proliferate. Activation of $\mathrm{ET}_{\mathrm{B}}$ on endothelial cells causes vasodilation and the clearance of ET-1 (44). In addition, PTEN has been reported to be a tumour suppressor gene. It translates dual-specificity protein phosphatase that is involved in tumour suppression. Moreover, PTEN mutation is frequently found to be associated with many human cancers, such as endometrial carcinomas, breast carcinomas, prostate carcinomas and gliomas (45), as well as canine osteosarcoma cell lines and tumours (46). SLC39A7 is a zinc transporter that transports zinc across the cytoplasm into the cell from the extracellular compartment or transports zinc into the cell from intracellular organelles, such as the endoplasmic reticulum (ER), Golgi apparatus and mitochondria (47). CLN6 is a ceroid-lipofuscinosis neuronal protein 6 homologue. A mutation of CLN6 would result in neuronal ceroid lipofuscinoses (NCLs), the most common neurodegenerative diseases, which primarily occur in children (48). The detection of CLN6-induced NCL has also been reported in some breeds of dogs, including Border Collies, English Setters, American Bulldogs, Dachshunds and Australian Shepherds (49). Four of the 6 proteins, including CLCN1, EDNRA, PTEN and SLC39A7, were found to associate with cardiovascular drugs, as demonstrated in the protein network interaction analysis (Fig. 4). If the peptide candidates obtained from this study were derived from the degradation of these specified proteins, it was suggested that they may be involved in the pathogenesis of PH and MVD as predicted by the Stitch program. SLC39A7 and CLUL1 showed no relationship with cardiovascular drugs or other proteins in the pathway. This possibly suggests that these 2 proteins could be novel candidate biomarkers whose association with cardiovascular disorders has never before been identified. 
Differential protein expression has been reported in Cavalier King Charles Spaniel (CKCS) dogs affected by MVD with different severity levels by MALDI-TOF MS using serum samples (50). The candidate peptides obtained from this current study were all different from those in the previous study, which is probably due to the different techniques of peptide identification (MALDI-TOF/TOF vs LC-MS/MS) and different breeds of dogs enrolled (CKCS vs no limitation on breed).

This study demonstrates a promising finding for the diagnosis of MVD and PH in dogs using MALDI-TOF in combination with LC-MS/MS. However, there are several limitations to this study. First, there was a small sample size in the MVD B PH group. This group consists of dogs with MVD stage B2 and secondary PH. Since MVD stage B2 is an asymptomatic stage, the left atrial pressure that would affect the pulmonary circulation is expected to be lower than that in the symptomatic stage of MVD (MVD stage $\mathrm{C} 2$ ). Hence, secondary PH is less likely to develop in dogs with MVD stage B2 than those with MVD stage C2. For this reason, fewer samples were collected for the MVD B PH group than for the other groups. Another limitation is that several factors, including age, sex, breed and previous treatment, could not be controlled. These factors could confound the outcome of the study. Nevertheless, our results obtained using pooled samples show different profiles of peptide barcode patterns among all 5 groups. This indicates that these factors would not affect the results of this study. Additionally, the results from individual samples in each group were obtained using 3D-PCA before the pooled samples were analysed to exclude samples with peptide expression that deviated from that of most of the samples within the group.

This was a pilot study, and further investigations with more samples from dogs affected by MVD stage $\mathrm{B} 2$ with $\mathrm{PH}$, as well as more dogs with the same heart disease condition but with different ages, sexes and breeds, are expected to be performed to support and verify the results of the current study. However, the different peptide barcodes among all 5 groups initially confirm the differences in peptide expression among dogs with different heart disease conditions. Further studies on peptide and protein expression in dogs with MVD and $\mathrm{PH}$ are recommended.

\section{Conclusion}

This present study shows an advantage of peptidomic study using MALDI-TOF MS in providing useful information for the diagnosis of MVD with different severities with and without PH. In combination with LC-MS/MS, MALDI-TOF MS revealed candidate peptides associated with the disease conditions. In this study, different peptide barcodes and discrete clusters of peptides were expressed among all groups, as determined by the 3D-PCA method. This indicates that MALDI-TOF has promise as an additional and alternative technique for the detection of canine MVD and PH with different clinical conditions. The obtained outcome of specific peptide barcodes in dogs with different types of heart diseases may contribute to the development of novel diagnostic methods for patients with heart diseases. These findings appear to be helpful for the future diagnosis of many diseases in veterinary medicine. However, more information from the numbers of samples in dogs with other diseases, apart from heart disease, is required to identify peptide barcodes to establish a large database of peptide barcode libraries in 
veterinary medicine. Then, this method could be used as a rapid test for the diagnosis and discrimination of asymptomatic and symptomatic MVD with and without $\mathrm{PH}$, as well as other important canine diseases in the future.

\section{Methods}

\section{Sample collection}

Blood samples were collected from dogs that were submitted as clinical cases at Prasu-Arthorn Animal Hospital, Faculty of Veterinary Science, Mahidol University, Thailand. Informed consent was obtained from all owners before their dogs were enrolled in the study. The protocol used in this study was approved by the Mahidol University-Institute Animal Care and Use Committee of the Faculty of Veterinary Science. The study was prospectively conducted from March 2018 to August 2019. Dogs were required to be at least 5 years old with no limit on sex, breed or weight for inclusion in the study. All dogs underwent history taking and a complete physical examination. The cardiorespiratory system was evaluated using thoracic auscultation to check for the presence/absence of a heart murmur, as well as the type, type, location and intensity (grade I-VI) of the heart murmur.

Thoracic radiographs were obtained in right lateral and ventrodorsal (VD) or dorsoventral (DV) recumbency for all recruited dogs. Evidence of cardiomegaly, left- and/or right-sided heart enlargement, pulmonary venous congestion, main pulmonary arterial dilatation and pulmonary oedema was evaluated. Electrocardiography (ECG) was performed using a standard six-lead recording system in right lateral recumbency. Six-lead ECG data were recorded for approximately 10 seconds in each dog. Further oneminute recording of the cardiac rhythm by lead II was performed if arrhythmia was detected.

The echocardiographic examination was performed by one well-trained investigator using a GE Vivid E9 ultrasound machine with a multi-frequency sector transducer (4.5-12 MHz probe) with continuous ECG recording during the process. The enrolled dogs were not sedated during the procedure, and all measurements were repeated for at least three consecutive cardiac cycles. The right parasternal (RPS) long-axis view on 2-dimensional (2D) echocardiography was used to assess valve structure and function, including valve degeneration, valvular prolapse and chordae tendineae rupture. Colour flow Doppler was used to identify the presence of valvular regurgitation and consider the degree of mitral regurgitation (MR) semi-quantitatively. The left atrial-to-aorta (LA/Ao) ratio was measured during diastole in the RPS short-axis 2D view to identify the presence of left atrial dilatation (51). The size of the main pulmonary artery (PA) was also assessed in the 2D RPS short axis. Short-axis M-mode echocardiographic examination of the left ventricle was used to demonstrate left ventricular function and determine the left ventricular internal diameter in the diastolic phase (LVIDd) and the left ventricular internal diameter in the systolic phase (LVIDs). To normalize these values based on body weight, the LVIDd (cm) was divided by (body weight (kg) ${ }^{0.294}$ and the LVIDs (cm) was divided by (body weight (kg)) ${ }^{0.315}$ to obtain the normalized left ventricular internal diameter in the diastolic phase (NLVIDd) and the normalized left ventricular internal diameter in the systolic phase (NLVIDs), respectively (52). 
The left parasternal (LPS) apical 4-chamber view, LPS long-axis view of the right auricle and LPS cranial transverse view of the tricuspid valve that provided the optimal alignment of the continuous wave beam and tricuspid regurgitation (TR) flow were used to measure the maximal flow velocity of the TR jet. Peak TR flow measurement was applied using the modified Bernoulli equation (Pressure gradient $(P G)=4 x$ velocity $^{2}$ ) to calculate the systolic PG across the tricuspid valve, which can represent the systolic PAP. A peak TR jet velocity higher than $2.8 \mathrm{~m} / \mathrm{s}$ and a PAP equal to or greater than $31 \mathrm{mmHg}$ indicate $\mathrm{PH}$. Pulmonary stenosis was ruled out before the diagnosis of $\mathrm{PH}$ was made decisively by measuring the peak pulmonary artery flow velocity, which should be lower than $1.5 \mathrm{~m} / \mathrm{s}$ without turbulent flow across the pulmonary valve.

Dogs were excluded from the study if they were found to have other significant concurrent systemic diseases, such as renal disease, hepatic disease, hormonal disease, or gastrointestinal disease, which may interfere with protein expression. Dogs with any other congenital or acquired heart diseases other than MVD were also excluded from the study. However, dogs that received standard therapy to stabilize congestive heart failure, such as diuretics, angiotensin-converting enzyme inhibitors (ACEls), inotropic agents and vasodilators, were all permitted to participate in this study.

Fifty-nine dogs were enrolled in the study. They were classified into 5 groups according ACVIM classification from the guidelines for the diagnosis and treatment of mitral valve disease in dogs (29) and further subdivided according to the presence/absence of $\mathrm{PH}$.

The MVD B group included 16 dogs with MVD stage B2, i.e., dogs affected by MVD with no clinical signs of congestive heart failure (asymptomatic patients). No radiographic evidence of congestive heart failure and no evidence of pulmonary oedema and/or venous congestion was detected, but there was sufficient haemodynamic change to cause echocardiographic evidence of left atrial dilatation with an LA/Ao ratio greater than 1.6 (51) and left ventricular enlargement with a LVIDDN greater than 1.7 (52).

The MVD B PHgroup included 5 dogs affected by MVD stage B2 with PH, i.e., dogs affected by MVD with secondary PH but with no clinical signs of congestive heart failure (asymptomatic patients). The criteria for classifying MVD stage B were similar to those mentioned above in group MVD B. Dogs with PH were classified by Doppler echocardiography assessing a peak TR velocity greater than or equal to $2.8 \mathrm{~m} / \mathrm{s}$ and/or pulmonary regurgitant velocity greater than or equal to $2.2 \mathrm{~m} / \mathrm{s}(10)$.

The MVD C group included 11 dogs with MVD stage C, i.e., dogs affected by MVD with echocardiographic evidence of MVD and clinical signs of congestive heart failure (symptomatic patients), identified by clinical examination and radiographic evidence of pulmonary oedema and/or pulmonary venous congestion.

The MVD C PH group included 16 dogs affected by MVD stage $\mathrm{C}$ with $\mathrm{PH}$, i.e., dogs affected by MVD with secondary PH with clinical signs of congestive heart failure (asymptomatic patients). The criteria for classifying MVD stage $\mathrm{C}$ and $\mathrm{PH}$ wee similar to those mentioned above. 
The normalcontrol group comprised 11 normal healthy control dogs with no heart disease or $\mathrm{PH}$, referred to as the NC group. These had no history or clinical signs of cardiorespiratory diseases, such as coughing, dyspnoea, exercise intolerance, cyanosis or syncope. No heart murmurs or crackle lung sounds were detected by auscultation. Each animal was inspected by thoracic radiography, ECG and echocardiography to ensure that the animal had a normal heart condition. The age of the dogs enrolled in this group was matched with that of the dogs in the other groups.

Baseline characteristics of all dogs were compared among the 5 groups using SPSS software version 24 . A normal distribution could not be assumed due to the small sample size; therefore, all numeric variables were analysed with nonparametric tests. The Kruskal-Wallis test was used to analyse continuous variables, and the chi-square test was used for categorical variables.

\section{Sample preparation}

Five millilitres of blood was taken from the jugular vein or saphenous vein for routine haematology and serum biochemistry. The first portion, consisting of $0.5 \mathrm{ml}$, was transferred into an ethylenediaminetetraacetate (EDTA) tube for a complete blood count (CBC). The second portion, consisting of $1.5 \mathrm{ml}$, was transferred into a heparinized tube for biochemical analysis, including the determination of alanine aminotransferase (ALT), alkaline phosphatase (ALP), creatinine, blood urea nitrogen (BUN), total protein (TP) and albumin. The remaining $3 \mathrm{ml}$ of blood was stored in a serum tube for the peptidomic process. Serum samples were separated by centrifugation at $4^{\circ} \mathrm{C}$ and $3000 \mathrm{~g}$ for 10 minutes within 30 minutes after collection. Subsequently, each sample was aliquoted and kept at $-80^{\circ} \mathrm{C}$ for subsequent analyses. The total protein concentration in each serum sample was evaluated by Lowry's assay at $690 \mathrm{~nm}$ using bovine serum albumin (BSA) as a standard (53).

\section{Analysis of serum peptides by MALDI-TOF MS}

The serum samples in each group were prepared at a concentration of $1 \mathrm{mg} / \mathrm{ml}$ in $0.1 \%$ trifluoroacetic acid (TFA). The whole serum was pooled for $10 \mu \mathrm{L}$ per sample at a concentration of $1 \mathrm{mg} / \mathrm{ml}$. The pooled samples were then mixed with MALDI matrix solution consisting of $10 \mathrm{mg} / \mathrm{ml} \mathrm{a-cyno-4-hydroxycinnamic}$ acid (CHCA) in 100\% acetonitrile (ACN) containing 5\% TFA at a ratio of 1:3 (sample:matrix), and $2 \mu \mathrm{L}$ of the mixed samples was directly spotted on the MALDI steel target plate (MTP 384 ground steel, Bruker Daltonics, Billerica, Massachusetts, USA) with 36 replicates. After air drying, mass spectra were developed by an Ultraflex III TOF/TOF system (Bruker Daltonics) in a linear positive mode with a mass range of 1,000-20,000 Da. External calibration was performed using the Proteo-Mass Peptide \& Protein MALDI MS Calibration Kit (Sigma Aldrich, St. Louis, Missouri, USA), including human angiotensin II $(1,046.5423 \mathrm{~m} / \mathrm{z})$, synthetic peptide P14R $(1,533.8582 \mathrm{~m} / \mathrm{z})$, human ACTH fragment 18-39 $(2,465.1989$ $\mathrm{m} / \mathrm{z})$, bovine insulin oxidized B chain $(3,494.6513 \mathrm{~m} / \mathrm{z})$, bovine insulin $(5,735 \mathrm{~m} / \mathrm{z})$, equine cytochrome $\mathrm{c}$ $(12,362 \mathrm{~m} / \mathrm{z})$ and equine apomyoglobin $(16,952 \mathrm{~m} / \mathrm{z})$. The mass spectra of peptide barcodes were analysed by Flex Analysis version 3.3 software (Bruker Daltonics). Dendrograms and three-dimensional principal component analysis (3D PCA) scatterplots were analysed by ClinPro Tools version 3.0 software 
(Bruker Daltonics) (54). To analyse the differences in the peptide mass spectra among the groups, the Wilcoxon test was used. A P-value $<0.05$ was considered statistically significant.

Peptide identification by LC-MS/MS

Peaks of peptide mass spectra with high signal intensities were further selected to be evaluated by LCMS/MS to identify specific peptide sequences. Serum samples were purified by C18 ZipTip (Merck Millipore, Darmstadt, Germany) and diluted with $2 \%$ ACN. Next, serum samples were analysed by LCMS/MS. An ultimate 3000 LC system (Thermo Scientific Dionex, Waltham, MA, US) on a nanocolumn (PepSwift monolithic column, $100 \mu \mathrm{m}$ in diameter $\times 50 \mathrm{~mm}$ in length) connected to an electrospray ionization system in positive ion mode and a Hybrid quadrupole Q-TOF impact I ${ }^{\mathrm{TM}}$ system (Bruker Daltonics $\mathrm{GmbH}$, Germany) was used. MaxQuant (version 1.6.6.0) was used for peptide identification against the UniProt data for Canis lupus familiaris (55). The relationship of peptide candidates and common cardiovascular drugs was demonstrated using Stitch version 5.0 (56).

\section{Abbreviations}

2D: Two-dimensional, 3D-PCA: Three-dimensional Principal Component Analysis, ACE: Angiotensinconverting enzyme, ACEls: Angiotensin-converting enzyme inhibitors, ACN: Acetonitrile, ACVIM: American College of Veterinary Internal Medicine, AKT1: v-akt murine thymoma viral oncogene homologue 1, ALP: Alkaline phosphatase, ALT: Alanine aminotransferase, BSA: bovine serum albumin, BUN: Blood urea nitrogen, CBC: Complete blood count, CHCA: cyno-4-hydroxycinnamic acid ,CHF: Congestive heart failure, CIC-1: Chloride channel protein 1, CKCS: Cavalier King Charles Spaniel, CLCN1: Chloride channel protein 1; CLN6: Ceroid-lipofuscinosis neuronal protein 6 homologue, CLUL1: Clusterin-like protein 1 precursor, cTnl: Cardiac troponin I, DV: Dorsoventral, ECG: Electrocardiography, EDN-1: Endothelin-1, EDNRA: Endothelin-1 receptor precursor, EDTA: Ethylenediaminetetraacetate, ET-1: Endothelin-1, ET A: Endothelin receptor type $A, E_{B}$ : Endothelin receptor type B, FS\%: percentage of fractional shortening, InsP3: intracellular messenger formed by the action of phospholipase $C$ on phosphatidylinositol 4,5bisphosphate, LA:Ao: Left atrium-to-aorta, LC-MS/MS: Liquid chromatography tandem mass spectrometry, LPS: Left parasternal, MALDI-TOF MS: Matrix-assisted laser desorption/ionization time-offlight mass spectrometry, mmHg: millimeters of mercury, MR: Mitral regurgitation, MVD: Mitral valve disease, MVD B: Mitral valve disease stage B, MVD B PH: Mitral valve disease stage B with pulmonary hypertension, MVD C: Mitral valve disease stage C, MVD C PH: Mitral valve disease stage $C$ with pulmonary hypertension, m/z: Mass per charge, NCLs: neuronal ceroid lipofuscinoses, NLVIDd: Normalized end-diastolic left ventricular internal diameter, NLVIDs: Normalized end-systolic left ventricular internal diameter, NT-proBNP: N-terminal pro B-type-natriuretic peptide, PA: Pulmonary artery, PAP: Pulmonary arterial pressure, PDE5A: Phodiesterase 5, PH: Pulmonary hypertension, Ptdlns:

Phosphatidic acid combined with inositol, PTEN: Phosphatidylinositol-3,4,5-trisphosphate 3-phosphatase and dual-specificity protein phosphatase, PTK2: Protein tyrosine kinase 2, SLC39A7: Zinc transporter SLC39A7, TFA: trifluoroacetic acid, TR: Tricuspid regurgitation, VD: Ventrodorsal 


\section{Declarations}

\section{Ethics approval and consent to participate}

Ethics approval was permitted by Mahidol University-Institute Animal Care and Use Committee of Faculty of Veterinary Science. Informed consents were signed from all owners before their dogs were enrolled into the study.

\section{Consent for publication}

Not applicable

\section{Availability of data and materials}

The datasets used and analysed during the study are available from the corresponding author upon request.

\section{Competing interests}

The authors declare that they have no competing interests.

\section{Funding}

This study was supported by the Faculty of Veterinary Science, Mahidol University, and a research assistant (RA) scholarship from the Faculty of Graduate Studies, Mahidol University Academic Year 2019. The funding was mainly used for clinical procedures, including echocardiography, radiography, electrocardiography, hematology, and biochemical profiles. The funders had no involvement in the design, sample collection, and analysis of the study.

\section{Author's contributor}

NR and SR committed study design and conceptualization. NR and SR organized the project study. NR performed the sample collection. JJ, NP and SC performed the laboratory analysis. NR prepared initial draft of manuscript. SR and WS made revision and refinement of the manuscript. SR and WS applied for project's funding. All authors had read and approved the final manuscript.

\section{Acknowledgements}

We sincerely thank all staff at Functional Proteomics Technology Laboratory, National Centre for Genetic Engineering and Biotechnology (BIOTEC), Pathum Thani, Thailand, for laboratory assistance and support. We would like to thank all staff at the laboratory centre, Prasu-Arthorn Animal Hospital, Faculty of Veterinary Science, Mahidol University, Nakhon Pathom, Thailand, for sample processing assistance. Special thanks to Dr. Nathamon Yimpring and Dr. Sekkarin Ploypetch for technical advice during the study. 
Author'sinformation

${ }^{1}$ Prasu-Arthorn Animal Hospital, Faculty of Veterinary Science, Mahidol University, 999 Phutthamonthon Sai 4 Road, Salaya, Phutthamonthon, Nakhon Pathom, 73170, Thailand, ${ }^{2}$ Functional Proteomics Technology Laboratory, National Centre for Genetic Engineering and Biotechnology (BIOTEC), National Science and Technology Development Agency, 113 Thailand Science Park, Phahonyothin Road, Klong Nueng, Khlong Luang, Pathum Thani, 12120, Thailand, ${ }^{3}$ Department of Clinical Sciences and Public Health, Faculty of Veterinary Science, Mahidol University, 999 Phutthamonthon Sai 4 Road, Salaya, Phutthamonthon Nakhon Pathom, 73170, Thailand.

\section{References}

1. Pyle RL, Abbott J, MacLean H. Pulmonary hypertension and cardiovascular sequelae in 54 dogs. Intern J Appl Res Vet Med. 2004;2(2):99-109.

2. Johnson L, Boon J, Orton EC. Clinical characteristics of 53 dogs with Doppler-derived evidence of pulmonary hypertension: 1992-1996. J Vet Intern Med. 1999;13(5):440-7.

3. Kellum HB, Stepien RL. Sildenafil citrate therapy in 22 dogs with pulmonary hypertension. J Vet Intern Med. 2007;21(6):1258-64.

4. Simonneau G, Galie N, Rubin LJ, Langleben D, Seeger W, Domenighetti G, et al. Clinical classification of pulmonary hypertension. J Am Coll Cardiol. 2004;43(12 Suppl S):5S-12S.

5. Serres F, Chetboul V, Gouni V, Tissier R, Sampedrano CC, Pouchelon JL. Diagnostic value of echoDoppler and tissue Doppler imaging in dogs with pulmonary arterial hypertension. J Vet Intern Med. 2007;21(6):1280-9.

6. Johnson L, Boon J, Orton EC. Clinical characteristics of 53 dogs with Doppler-derived evidence of pulmonary hypertension: 1992-1996. Journal of Veterinary Internal Medicine. 1999;13(5):440-7.

7. Borgarelli M, Crosara S, Lamb K, Savarino P, La Rosa G, Tarducci A, et al. Survival characteristics and prognostic variables of dogs with preclinical chronic degenerative mitral valve disease attributable to myxomatous degeneration. J Vet Intern Med. 2012;26(1):69-75.

8. McLaughlin VV, Archer SL, Badesch DB, Barst RJ, Farber HW, Lindner JR, et al. ACCF/AHA 2009 expert consensus document on pulmonary hypertension: a report of the American College of Cardiology Foundation Task Force on Expert Consensus Documents and the American Heart Association: developed in collaboration with the American College of Chest Physicians, American Thoracic Society, Inc., and the Pulmonary Hypertension Association. Circulation. 2009;119(16):2250-94.

9. Haggstrom J, Duelund Pedersen H, Kvart C. New insights into degenerative mitral valve disease in dogs. Vet Clin North Am Small Anim Pract. 2004;34(5):1209-26, vii-viii. 
10. Kellihan HB, Stepien RL. Pulmonary hypertension in canine degenerative mitral valve disease. J Vet Cardiol. 2012;14(1):149-64.

11. Atkinson KJ, Fine DM, Thombs LA, Gorelick JJ, Durham HE. Evaluation of pimobendan and Nterminal probrain natriuretic peptide in the treatment of pulmonary hypertension secondary to degenerative mitral valve disease in dogs. J Vet Intern Med. 2009;23(6):1190-6.

12. Kellihan HB, Mackie BA, Stepien RL. NT-proBNP, NT-proANP and cTnl concentrations in dogs with precapillary pulmonary hypertension. J Vet Cardiol. 2011;13(3):171-82.

13. Guglielmini C, Civitella C, Diana A, Di Tommaso M, Cipone M, Luciani A. Serum cardiac troponin I concentration in dogs with precapillary and postcapillary pulmonary hypertension. J Vet Intern Med. 2010;24(1):145-52.

14. Oyama MA, Fox PR, Rush JE, Rozanski EA, Lesser M. Clinical utility of serum N-terminal pro-B-type natriuretic peptide concentration for identifying cardiac disease in dogs and assessing disease severity. $J$ Am Vet Med Assoc. 2008;232(10):1496-503.

15. Oyama MA, Rush JE, Rozanski EA, Fox PR, Reynolds CA, Gordon SG, et al. Assessment of serum Nterminal pro-B-type natriuretic peptide concentration for differentiation of congestive heart failure from primary respiratory tract disease as the cause of respiratory signs in dogs. J Am Vet Med Assoc. 2009;235(11):1319-25.

16. Angeletti S. Matrix assisted laser desorption time of flight mass spectrometry (MALDI-TOF MS) in clinical microbiology. J Microbiol Methods. 2017;138:20-9.

17. Zhang $\mathrm{MH}, \mathrm{Xu} \mathrm{XH}$, Wang $\mathrm{Y}$, Linq QX, Bi YT, Miao XJ, et al. A prognostic biomarker for gastric cancer with lymph node metastases. Anat Rec (Hoboken). 2013;296(4):590-4.

18. Pastor MD, Nogal A, Molina-Pinelo S, Melendez R, Salinas A, Gonzalez De la Pena M, et al. Identification of proteomic signatures associated with lung cancer and COPD. J Proteomics. 2013;89:22737.

19. Gianazza E, Chinello C, Mainini V, Cazzaniga M, Squeo V, Albo G, et al. Alterations of the serum peptidome in renal cell carcinoma discriminating benign and malignant kidney tumors. J Proteomics. 2012;76 Spec No.:125-40.

20. Schwamborn K, Krieg RC, Grosse J, Reulen N, Weiskirchen R, Knuechel R, et al. Serum proteomic profiling in patients with bladder cancer. Eur Urol. 2009;56(6):989-96.

21. Nilsson CL, Berven F, Selheim F, Liu H, Moskal JR, Kroes RA, et al. Chromosome 19 annotations with disease speciation: a first report from the Global Research Consortium. J Proteome Res. 2013;12(1):13550 . 
22. Teiten MH, Gaigneaux A, Chateauvieux S, Billing AM, Planchon S, Fack F, et al. Identification of differentially expressed proteins in curcumin-treated prostate cancer cell lines. OMICS. 2012;16(6):289300 .

23. Montgomery H, Rustogi N, Hadjisavvas A, Tanaka K, Kyriacou K, Sutton CW. Proteomic profiling of breast tissue collagens and site-specific characterization of hydroxyproline residues of collagen alpha-1(I). J Proteome Res. 2012;11(12):5890-902.

24. Bohm D, Keller K, Wehrwein N, Lebrecht A, Schmidt M, Kolbl H, et al. Serum proteome profiling of primary breast cancer indicates a specific biomarker profile. Oncol Rep. 2011;26(5):1051-6.

25. Qin XJ, Ling BX. Proteomic studies in breast cancer (Review). Oncol Lett. 2012;3(4):735-43.

26. Kazmierczak M, Luczak M, Lewandowski K, Handschuh L, Czyz A, Jarmuz M, et al. Esterase D and gamma 1 actin level might predict results of induction therapy in patients with acute myeloid leukemia without and with maturation. Med Oncol. 2013;30(4):725.

27. Pisamai S, Roytrakul S, Phaonakrop N, Jaresitthikunchai J, Suriyaphol G. Proteomic analysis of canine oral tumor tissues using MALDI-TOF mass spectrometry and in-gel digestion coupled with mass spectrometry (GeLC MS/MS) approaches. PLoS One. 2018;13(7):e0200619.

28. Ploypetch S, Roytrakul S, Jaresitthikunchai J, Phaonakrop N, Krobthong S, Suriyaphol G. Salivary proteomics of canine oral tumors using MALDI-TOF mass spectrometry and LC-tandem mass spectrometry. PLoS One. 2019;14(7):e0219390.

29. Keene BW, Atkins CE, Bonagura JD, Fox PR, Haggstrom J, Fuentes VL, et al. ACVIM consensus guidelines for the diagnosis and treatment of myxomatous mitral valve disease in dogs. J Vet Intern Med. 2019;33(3):1127-40.

30. Kang HS, Lee SC, Park YS, Jeon YE, Lee JH, Jung SY, et al. Protein and lipid MALDI profiles classify breast cancers according to the intrinsic subtype. BMC Cancer. 2011;11:465.

31. Serafim V, Shah A, Puiu M, Andreescu N, Coricovac D, Nosyrev A, et al. Classification of cancer cell lines using matrix-assisted laser desorption/ionization timeofflight mass spectrometry and statistical analysis. Int J Mol Med. 2017;40(4):1096-104.

32. Boswood A, Dukes-McEwan J, Loureiro J, James RA, Martin M, Stafford-Johnson M, et al. The diagnostic accuracy of different natriuretic peptides in the investigation of canine cardiac disease. $J$ Small Anim Pract. 2008;49(1):26-32.

33. Tarnow I, Olsen LH, Kvart C, Hoglund K, Moesgaard SG, Kamstrup TS, et al. Predictive value of natriuretic peptides in dogs with mitral valve disease. Vet J. 2009;180(2):195-201. 
34. Wolf J, Gerlach N, Weber K, Klima A, Wess G. Lowered N-terminal pro-B-type natriuretic peptide levels in response to treatment predict survival in dogs with symptomatic mitral valve disease. J Vet Cardiol. 2012;14(3):399-408.

35. Moonarmart W, Boswood A, Luis Fuentes V, Brodbelt D, Souttar K, Elliott J. N-terminal pro B-type natriuretic peptide and left ventricular diameter independently predict mortality in dogs with mitral valve disease. J Small Anim Pract. 2010;51(2):84-96.

36. de Lima GV, Ferreira FDS. N-terminal-pro brain natriuretic peptides in dogs and cats: A technical and clinical review. Vet World. 2017;10(9):1072-82.

37. Langhorn R, Willesen JL. Cardiac troponins in dogs and cats. J Vet Intern Med. 2016;30(1):36-50.

38. Missov ED, De Marco T. Clinical insights on the use of highly sensitive cardiac troponin assays. Clin Chim Acta. 1999;284(2):175-85.

39. Sawada Y, Suda M, Yokoyama H, Kanda T, Sakamaki T, Tanaka S, et al. Stretch-induced hypertrophic growth of cardiocytes and processing of brain-type natriuretic peptide are controlled by proproteinprocessing endoprotease furin. The Journal of biological chemistry. 1997;272(33):20545-54.

40. Chen TT, Klassen TL, Goldman AM, Marini C, Guerrini R, Noebels JL. Novel brain expression of ClC-1 chloride channels and enrichment of CLCN1 variants in epilepsy. Neurology. 2013;80(12):1078-85.

41. Zhang Q, Beltran WA, Mao Z, Li K, Johnson JL, Acland GM, et al. Comparative analysis and expression of CLUL1, a cone photoreceptor-specific gene. Invest Ophthalmol Vis Sci. 2003;44(10):4542-9.

42. Arai $\mathrm{H}$, Hori S, Aramori I, Ohkubo H, Nakanishi S. Cloning and expression of a cDNA encoding an endothelin receptor. Nature. 1990;348(6303):730-2.

43. Sakurai T, Yanagisawa M, Takuwa Y, Miyazaki H, Kimura S, Goto K, et al. Cloning of a cDNA encoding a non-isopeptide-selective subtype of the endothelin receptor. Nature. 1990;348(6303):732-5.

44. Kawanabe Y, Nauli SM. Endothelin. Cell Mol Life Sci. 2011;68(2):195-203.

45. Ali IU, Schriml LM, Dean M. Mutational spectra of PTEN/MMAC1 gene: a tumor suppressor with lipid phosphatase activity. J Natl Cancer Inst. 1999;91(22):1922-32.

46. Levine RA, Forest T, Smith C. Tumor suppressor PTEN is mutated in canine osteosarcoma cell lines and tumors. Vet Pathol. 2002;39(3):372-8.

47. Hara T, Takeda TA, Takagishi T, Fukue K, Kambe T, Fukada T. Physiological roles of zinc transporters: molecular and genetic importance in zinc homeostasis. J Physiol Sci. 2017;67(2):283-301.

48. Oresic K, Mueller B, Tortorella D. Cln6 mutants associated with neuronal ceroid lipofuscinosis are degraded in a proteasome-dependent manner. Biosci Rep. 2009;29(3):173-81. 
49. Katz ML, Farias FH, Sanders DN, Zeng R, Khan S, Johnson GS, et al. A missense mutation in canine CLN6 in an Australian shepherd with neuronal ceroid lipofuscinosis. J Biomed Biotechnol. 2011;2011:198042.

50. Locatelli C, Piras C, Riscazzi G, Alloggio I, Spalla I, Soggiu A, et al. Serum proteomic profiles in CKCS with Mitral valve disease. BMC Vet Res. 2017;13(1):43.

51. Hansson K, Häggström J, Kvart C, Lord P. Left atrial to aortic root indices using two-dimensional and M-mode echocardiography in cavalier King Charles spaniels with and without left atrial enlargement. Vet Radiol Ultrasound. 2002;43(6):568-75.

52. Cornell CC, Kittleson MD, Della Torre P, Haggstrom J, Lombard CW, Pedersen HD, et al. Allometric scaling of M-mode cardiac measurements in normal adult dogs. J Vet Intern Med. 2004;18(3):311-21.

53. Lowry OH, Rosebrough NJ, Farr AL, Randall RJ. Protein measurement with the Folin phenol reagent. The Journal of biological chemistry. 1951;193(1):265-75.

54. Chaiyarit P, Taweechaisupapong S, Jaresitthikunchai J, Phaonakrop N, Roytrakul S. Comparative evaluation of 5-15-kDa salivary proteins from patients with different oral diseases by MALDI-TOF/TOF mass spectrometry. Clin Oral Investig. 2015;19(3):729-37.

55. Tyanova S, Temu T, Cox J. The MaxQuant computational platform for mass spectrometry-based shotgun proteomics. Nat Protoc. 2016;11(12):2301-19.

56. Szklarczyk D, Santos A, von Mering C, Jensen LJ, Bork P, Kuhn M. STITCH 5: augmenting proteinchemical interaction networks with tissue and affinity data. Nucleic Acids Res. 2016;44(D1):D380-4.

\section{Figures}


PCA

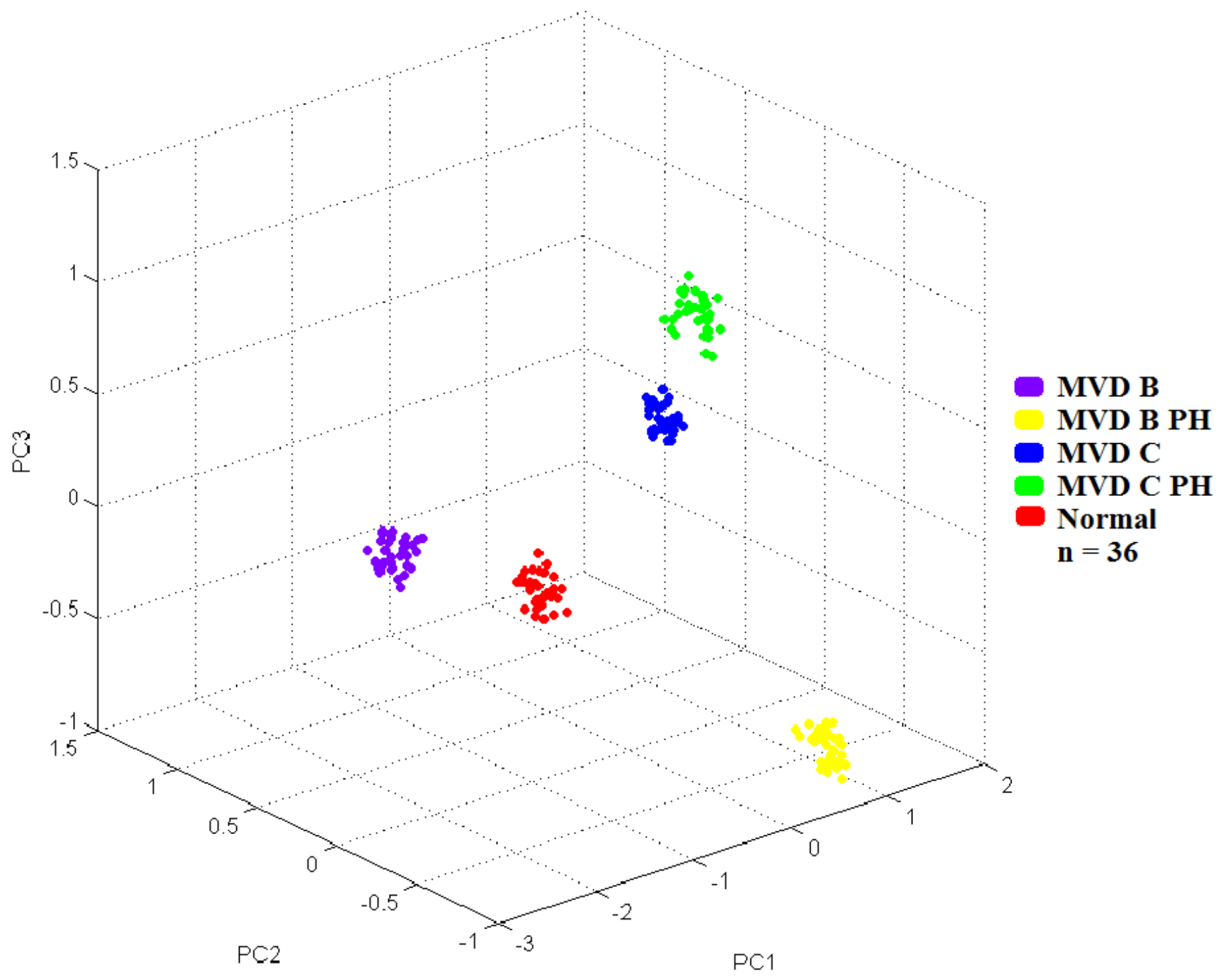

Figure 1

Three-dimensional principal component analysis (3D-PCA) scatterplot of dogs in the MVD stage B2 (MVD $B), M V D$ stage $B 2$ with $P H(M V D B P H), M V D$ stage $C$ (MVD C), MVD stage $C$ with $P H(M V D C P H)$ and normal control groups 


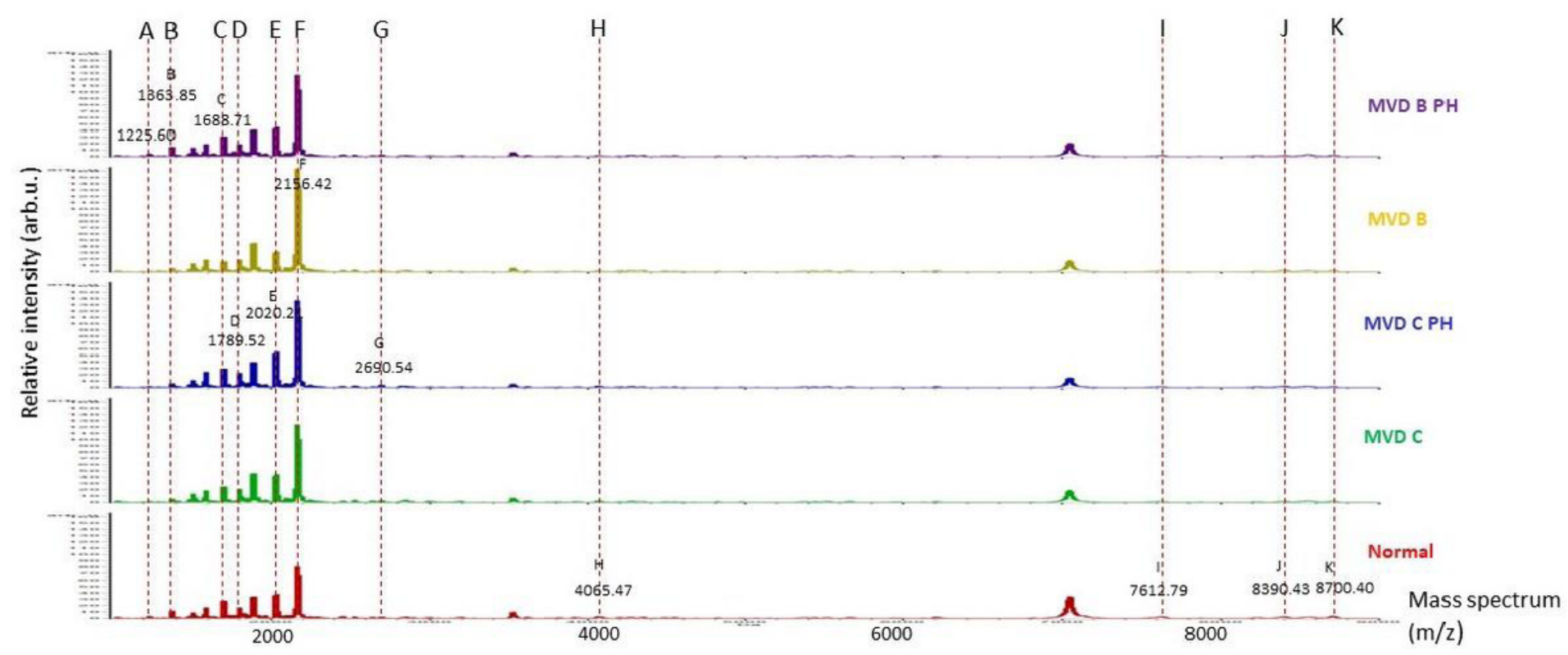

Figure 2

Peptide barcodes of dogs in the MVD stage B2 with PH (MVD B PH), MVD stage B2 (MVD B), MVD stage $C$ with $\mathrm{PH}(\mathrm{MVD} C \mathrm{PH}), \mathrm{MVD}$ stage $\mathrm{C}(\mathrm{MVD} C)$, and normal control groups in the detection range 1,000$20,000 \mathrm{Da}$ 

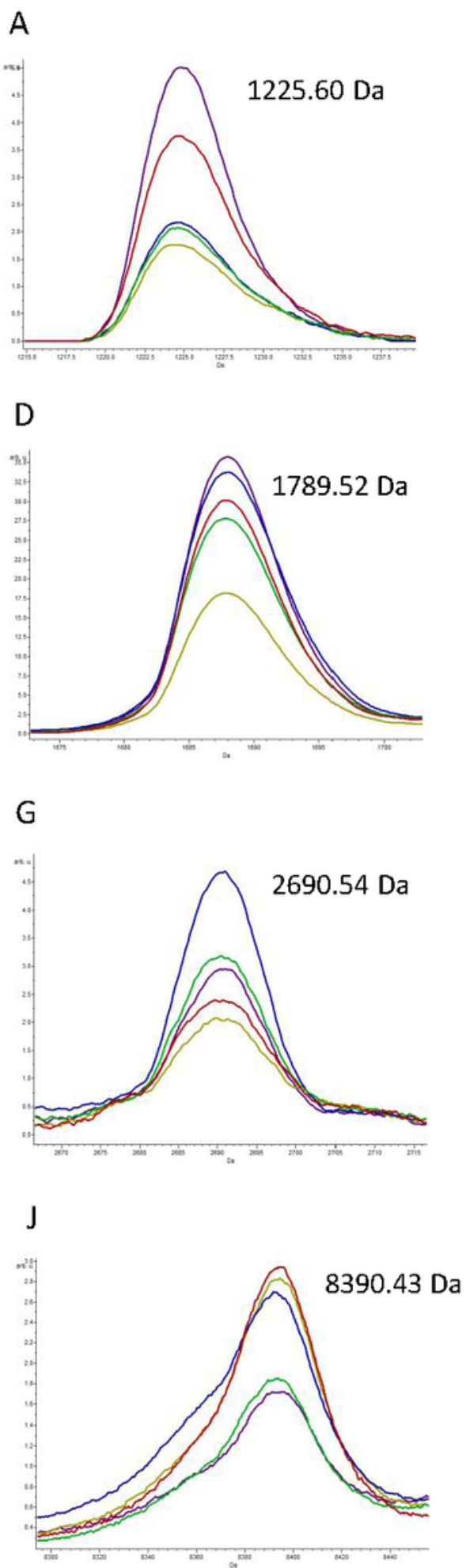

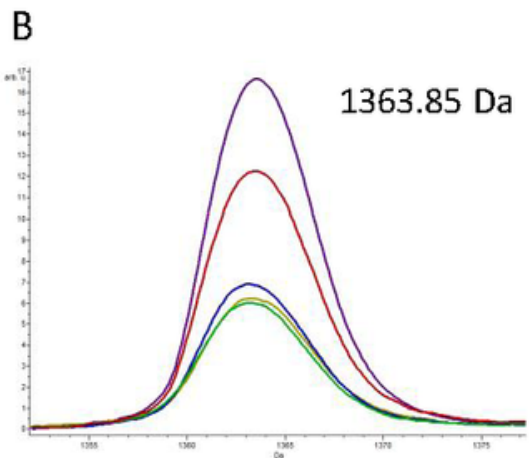

$\mathrm{E}$

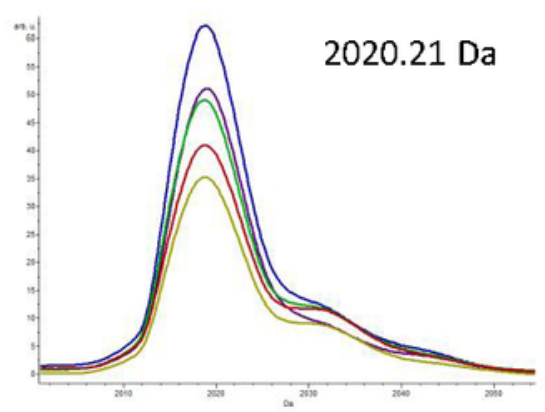

$\mathrm{H}$

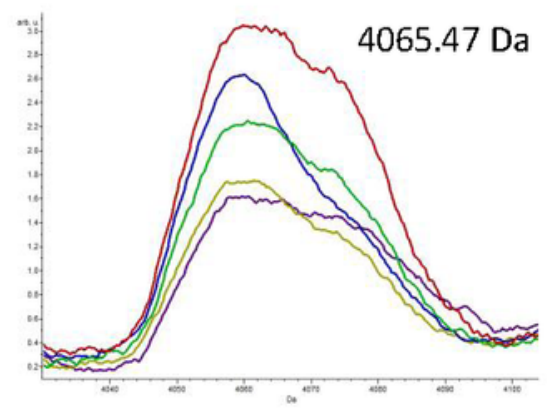

K

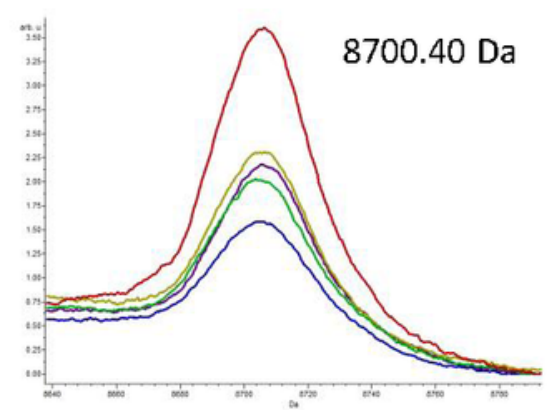

C
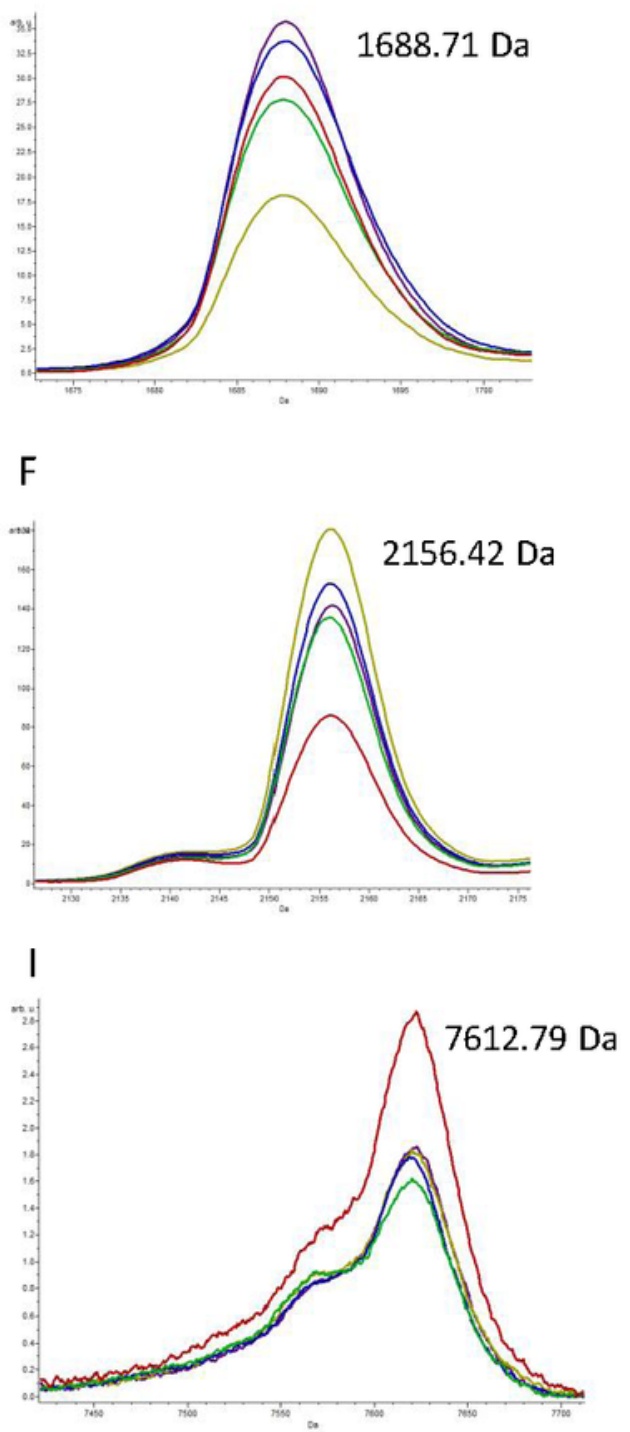

MVD B

MVD B PH

MVD C

MVD C PH

Normal

\section{Figure 3}

Magnified view of different mass spectral peaks of peptide barcodes among all 5 groups from Figure 2 


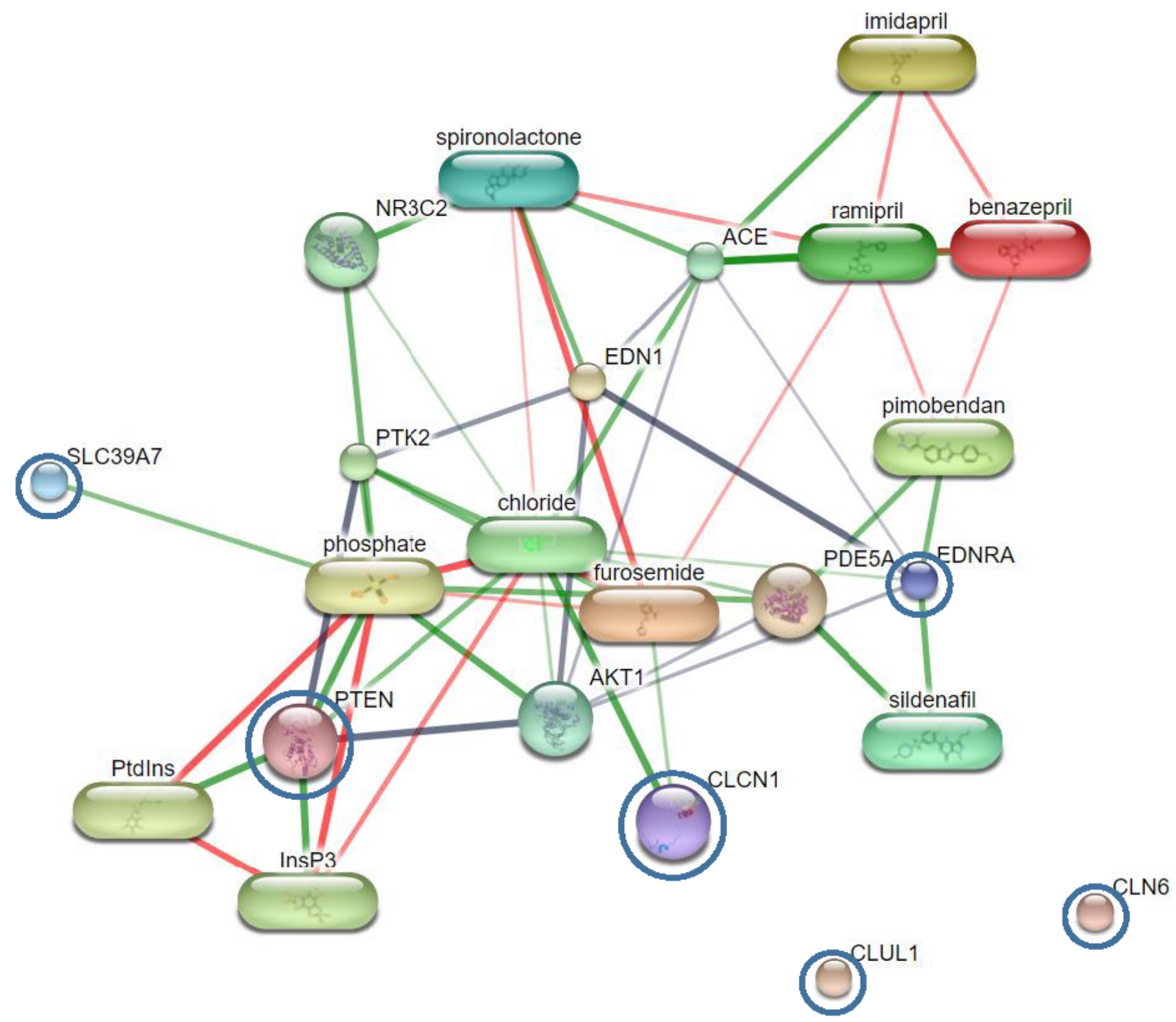

Figure 4

Relationships of CLCN1, EDNRA, PTEN, SLC39A7, CLUL1 and CLN6 proteins (blue circles) in the network of protein-cardiovascular drug interactions 